\title{
Avaliação da influência do envelhecimento e da temperatura nas características viscoelásticas de ligantes asfálticos
}

\author{
Laura Nascimento Mazzoni ${ }^{1}$, Marcia Midori Takahashi ${ }^{2}$, Kamilla Lima Vasconcelos ${ }^{3}$, \\ Liedi Bernucci ${ }^{4}$
}

1Escola Politécnica, Universidade de São Paulo, São Paulo - Brasil, laura.mazzoni@usp.br 2Escola Politécnica, Universidade de São Paulo, São Paulo - Brasil, marcia.takahashi@gmail.com ${ }^{3}$ Escola Politécnica, Universidade de São Paulo, São Paulo - Brasil, kamilla.vasconcelos@usp.com ${ }^{4}$ Escola Politécnica, Universidade de São Paulo, São Paulo - Brasil, liedi@usp.br

\section{Recebido:}

29 de novembro de 2018

Aceito para publicação:

4 de junho de 2019

Publicado:

30 de abril de 2020

Editor de área:

Jorge Barbosa Soares

\section{Palavras-chaves:}

Região viscoelástica linear,

Asfalto modificado,

Propriedades reológicas,

Envelhecimento de curto prazo,

Reologia.

\section{Keywords:}

Linear viscoelastic region,

Modified asphalt,

Rheological properties,

Short-term aging,

Rheology.

DOI:10.14295/transportes.v28i1.1897

\begin{abstract}
RESUMO
As especificações SUPERPAVE (Superior Performing Asphalt Pavements) introduziram a caracterização reológica de ligantes asfálticos, atribuindo propriedades de engenharia aos mesmos. Devido à complexidade do comportamento viscoelástico dos ligantes, os parâmetros reológicos foram inicialmente propostos apenas na região viscoelástica linear (LVER). Sabe-se que a rigidez do material é influenciada diretamente pela frequência, temperatura e envelhecimento. Esse trabalho estudou o efeito da temperatura de ensaio e do nível de envelhecimento na região viscoelástica linear durante o ensaio de varredura de deformações usando o reômetro de cisalhamento dinâmico (DSR). O envelhecimento foi realizado em estufa de filme fino rotativo (RTFO). Foram avaliados três ligantes asfálticos: um ligante convencional, um 60/85-E modificado por SBS (copolímero em bloco de estireno-butadieno-estireno) e o outro altamente modificado (HiMA). Os resultados mostram que os ligantes têm sua região viscoelástica linear reduzida com o aumento do envelhecimento e a redução da temperatura. Os ligantes modificados apresentaram maiores LVER que o ligante convencional, principalmente em altas temperaturas.
\end{abstract}

\section{ABSTRACT}

The Superior Performing Asphalt Pavements (SUPERPAVE) specifications presented the use of rheological characterization of asphalt binders attributing engineering properties to them. Initially, the rheological characterization was proposed only within the linear viscoelastic region (LVER) due to the complexity of the viscoelastic behavior. It is known that frequency, temperature and aging influence the material stiffness and consequently the LVER. This paper evaluates the effect of the temperature and different aging levels at the LVER of asphalt binders by the strain sweep test using the Dynamic Shear Rheometer (DSR). Aging was performed using the Rolling Thin Film Oven (RTFO). Three different asphalt binders were evaluated: one neat asphalt binder, one modified by styrene-butadiene-styrene (SBS), and the last one was a highly modified (HiMA). By the results, it is possible to conclude that lower temperatures and higher aging levels reduce the LVER. Modified binders presented higher LVER than the conventional binder, mainly at high temperatures.

\section{INTRODUCÃO}

Os ligantes asfálticos são materiais viscoelásticos, uma vez que seu comportamento depende do tempo e da temperatura de ensaio, o que faz com que sua caracterização seja complexa. No começo dos anos 80, nos Estados Unidos, deu-se início ao Strategic Highway Research Program 
(SHRP), que teve como objetivo melhorar o desempenho, a durabilidade e a segurança das estradas. 0 programa permitiu o desenvolvimento de um conjunto de especificações, incluindo a especificação para ligantes asfálticos, Superior Performing Asphalt Pavements, conhecida como SUPERPAVE (Kennedy et al., 1994). Até então, os ligantes eram caracterizados por meio de ensaios empíricos em condições específicas de temperatura, sendo ineficientes na caracterização do comportamento dos materiais asfálticos, principalmente em campo, onde os mesmos estão sujeitos a diversas variações de temperatura e solicitações do tráfego.

A especificação SUPERPAVE foi o resultado da pesquisa descrita nos relatórios do SHRP e trata da caracterização reológica dos ligantes asfálticos, obtidas por meio do reômetro de cisalhamento dinâmico (DSR - Dynamic Shear Rheometer), para a determinação de suas propriedades viscoelásticas, do módulo de cisalhamento dinâmico $\left(\left|G^{*}\right|\right)$ e do ângulo de fase $(\delta)$. A premissa do método é que os ensaios sejam realizados na região viscoelástica linear (LVER - Linear viscoelastic region), na qual o módulo de cisalhamento dinâmico é independente da tensão (ou da deformação) de cisalhamento, e as tensões aplicadas são pequenas para causar danos estruturais, tornando possível a medida da propriedade reológica.

As respostas mecânicas dos materiais podem ser divididas em três regiões: linear, não-linear e dano. Elas dependem da taxa de carregamento, da temperatura de ensaio e da amplitude de solicitação de tensão ou de deformação. 0 material é dito linear quando atende, simultaneamente, aos princípios da homogeneidade e da superposição de Boltzmann. Anderson et al. (1994) propõem o monitoramento de $\left|G^{*}\right|$ por meio de uma varredura de tensão ou deformação, para definir a região de comportamento viscoelástico linear do material. Os mesmos autores assumiram, arbitrariamente, que o material permanece na região viscoelástica linear até que sua rigidez inicial reduza no máximo 5\%. Marasteanu e Anderson (2000) adotaram 90\% do valor inicial da rigidez, de acordo com a especificação provisória da AASHTO de 1998. A norma ASTM D7175 (2015) para caracterização de ligantes asfálticos com o reômetro de cisalhamento dinâmico considera que o material está na região viscoelástica linear enquanto o valor de $\left|G^{*}\right|$ for maior ou igual a 90\% do valor inicial, determinado de acordo com o Apêndice X1 da norma.

A avaliação das diferentes faixas de deformações para cada uma dessas zonas é muito importante para os ensaios de vida de fadiga em ligantes e misturas asfálticas. Alguns estudos separam a não-linearidade do dano para entender até qual tensão ou deformação o material se mantém íntegro (Castelo Branco, 2008; Di Benedetto et al., 2011). Já outros autores avaliam a região viscoelástica linear para os ensaios de fadiga. Tais ensaios devem ser realizados em determinadas faixas de deformações ou tensões para evitar a influência da não-linearidade, na qual o ligante pode acumular dano mais rapidamente devido a dissipação de energia, apresentando um desempenho diferente (Bahia et al., 1999; Kim et al., 2003; Mangiafico et al., 2015).

Diversos estudos discutem a importância da avaliação da região viscoelástica linear para a caracterização de ligantes asfálticos sem, no entanto, apresentar os resultados obtidos ou discussões a respeito (Saravanan, 2012; Padmarekha e Krishnan, 2013; Bressi et al., 2016). Já outros trabalhos avaliam os fatores que influenciam a linearidade dos ligantes asfálticos, como a frequência de carregamento, a temperatura de ensaio e o envelhecimento. Bahia et al. (1999) acompanharam a interação entre o limite da região viscoelástica linear, a frequência e a temperatura por meio de uma varredura de deformações variando de $1 \%$ até $50 \%$. As temperaturas consideradas foram de $10{ }^{\circ} \mathrm{C}, 22^{\circ} \mathrm{C}, 34^{\circ} \mathrm{C}, 46^{\circ} \mathrm{C}$ e $58{ }^{\circ} \mathrm{C}$, enquanto as frequências foram de $0,15 \mathrm{~Hz}, 1,5 \mathrm{~Hz}$ e $15 \mathrm{~Hz}$. Em relação à frequência, concluiu-se que para $15 \mathrm{~Hz}$, com o aumento da deformação, houve grande queda no $\left|G^{*}\right|$. Já nas frequências de $0,15 \mathrm{~Hz}$ e $1,5 \mathrm{~Hz}$ não houve 
muita variação de rigidez. Grilli et al. (2017) avaliaram o efeito da frequência em ligantes com diferentes níveis de envelhecimento. 0 aumento da frequência de 1,59 Hz (10 rad/s) para 15,92 Hz (100 rad/s) chegou a reduzir a deformação limite da região viscoelástica linear em até $50 \%$ para os ligantes ensaiados.

No mencionado estudo de Bahia et al. (1999), a baixas temperaturas, os ligantes tiveram a LVER reduzida com o aumento do $\left|\mathrm{G}^{*}\right|$. Airey et al. (2003) compararam a LVER de alguns ligantes e evidenciaram que a maior região viscoelástica linear ocorre a altas temperaturas, especialmente no ligante modificado por elastômero. Acredita-se que, nessas temperaturas, o polímero está governando o comportamento do ligante asfáltico modificado. Saravanan (2012), trabalhando com modelos lineares, nota a influência das altas temperaturas no aumento da região linear. $O$ mesmo comportamento foi observado por Grilli et al. (2017) e Diab e You (2017). Todos os resultados obtidos por tais pesquisadores foram por meio de ensaios de varredura de deformação.

Airey et al. (2003) também avaliaram a região viscoelástica linear por varredura de tensões, indicando que, quando o comportamento do material estava mais próximo ao viscoso, o mesmo se tornava mais dependente da tensão. Lucena et al. (2004) e Masad et al. (2008) usam varreduras de tensões, e, ao contrário dos demais estudos, afirmam que a LVER sofre redução com o aumento da temperatura. 0 mesmo comportamento é observado quando há redução da frequência de carregamento. Tais trabalhos não discutem sobre a diferença na resposta do material quando sujeito às diferentes formas de carregamento, pois a avaliação foi feita apenas para a correta realização dos ensaios de caracterização das propriedades reológicas dos ligantes.

Conforme observado na literatura, a temperatura de ensaio e frequência de carregamento têm grande influência na região LVER dos materiais asfálticos, evidenciando a sua dependência em relação ao módulo de cisalhamento dinâmico (Bahia et al., 1999; Airey et al., 2003; Anderson, 2004; Diab e You, 2017). Outro fator responsável pelo aumento da rigidez dos ligantes asfálticos é o seu envelhecimento. Ele acontece devido à oxidação, principalmente a altas temperaturas, durante a usinagem das misturas asfálticas (Read e Whiteoak, 2003). Dessa forma, a caracterização dos ligantes asfálticos, após o envelhecimento de curto prazo, é fundamental para a compreensão do comportamento do material em campo, uma vez que este está sujeito aos carregamentos somente após a usinagem.

Devido à alta viscosidade dos ligantes asfálticos modificados por polímeros, seus fabricantes sugerem o aumento da temperatura de usinagem, gerando um maior risco à integridade do material em caso de temperaturas em excesso. Para simular o envelhecimento de ligantes modificados em laboratório, alguns trabalhos propõem alterações no procedimento de envelhecimento em estufa rotativa de filme fino (RTFOT), devido à alta viscosidade do material (Bahia et al., 2001; Yan et al., 2017). Bahia et al. (2001) sugerem a inserção de esferas metálicas padronizadas dentro dos copos do RTFOT para aumentar a taxa de cisalhamento durante o ensaio e possibilitar a formação de um filme uniforme. Yan et al. (2017) avaliam o aumento da temperatura para $178{ }^{\circ} \mathrm{C}$ e $193{ }^{\circ} \mathrm{C}$ durante o ensaio RTFOT, comparando com o resultado do ensaio proposto por Bahia et al. (2001).

Pelos resultados apresentados por Masad et al. (2008), é possível inferir que o envelhecimento aumentou a região viscoelástica linear do ligante asfáltico, considerando a mesma temperatura e frequência, em uma varredura de tensões. Bressi et al. (2016) não apresentam os resultados da varredura de deformações, porém, comentam que o envelhecimento diminuiu a região viscoelástica linear para os três níveis de envelhecimento testados: virgem, RTFOT e 
RTFOT + PAV (Pressure Aging Vessel), sendo que a região viscoelástica linear foi decrescente com o nível de envelhecimento.

$\mathrm{Na}$ tentativa de reproduzir o ligante extraído do material fresado, Grilli et al. (2017) testam os ligantes em quatro níveis de envelhecimento: (i) material virgem; (ii) material após o RTFOT; (iii) material após RTFOT e PAV; (iv) material após RTFOT, PAV, e um segundo PAV. O material de nível de envelhecimento (iv) simula o material fresado após a reaplicação em campo, além de seu comportamento durante sua vida de serviço. Os resultados mostraram que a região viscoelástica linear é menor com o aumento do envelhecimento do material. Entre os níveis de envelhecimento mais elevados (iii) e (iv) houve diferença na região linear, o que indica que o material continua envelhecendo após o RTFOT + PAV. O envelhecimento após os dois procedimentos no PAV foi tão significativo que para a frequência alta (100 rad/s) e temperatura baixa $\left(5^{\circ} \mathrm{C}\right)$, o material apresentou a região viscoelástica linear quase inexistente, pouco maior que a deformação de $0,1 \%$, enquanto o ligante nas condições (i), (ii) e (iii) apresentaram a deformação limite da LVER de 1,2\%,1,2\% e 0,2\%, respectivamente. Coincidentemente, na maioria das condições de temperatura e frequência o limite da LVER foi igual para os níveis de envelhecimento (i) e (ii), incluindo as condições que levam o material a maior ou menor rigidez.

Neste contexto, o objetivo desse trabalho é avaliar a região viscoelástica linear de diferentes ligantes asfálticos em diferentes níveis de envelhecimento a partir de ensaios reológicos, variando a temperatura do ensaio. Para isso, foram avaliados três ligantes asfálticos: um ligante convencional, um modificado por SBS e um outro altamente modificado (HiMA - Highly Modified Asphalt Binder), também por SBS.

\section{MATERIAIS E MÉTODOS}

\subsection{Materiais}

Foram utilizados três ligantes asfálticos, um ligante convencional CAP 30/45 com classificação por grau de desempenho PG 64H-XX e dois modificados por polímeros SBS, um de classificação segundo a ANP (2010) 60/85E com PG 76H-XX e um HiMA com PG 82H-XX. O grau de desempenho (PG) das amostras foi obtido de acordo com a norma AASHTO M332 (2014), considerando um nível de tráfego pesado $(\mathrm{H})$ com número de solicitações entre 1 x $10^{6}$ e 3 x $10^{6}$ ESAL (Equivalent Single Axle Loads) somente para temperatura alta do PG. A caracterização dos ligantes asfálticos é apresentada na Tabela 1. Os ligantes asfálticos analisados no estudo apresentam características bem diferentes. Pela classificação do PG, os ligantes modificados apresentam desempenho superior ao ligante convencional em temperaturas elevadas, para um mesmo nível de tráfego.

Tabela 1 - Caracterização dos ligantes asfálticos

\begin{tabular}{|c|c|c|c|c|c|c|c|}
\hline \multirow{2}{*}{ Ligante } & \multirow{2}{*}{$\begin{array}{l}\text { Penetração } \\
(0,1 \mathrm{~mm})\end{array}$} & \multirow{2}{*}{$\begin{array}{l}\text { Ponto de } \\
\text { Amolecimento }\left({ }^{\circ} \mathrm{C}\right)\end{array}$} & \multicolumn{3}{|c|}{ Viscosidade Brookfield (cP) } & \multirow{2}{*}{$\begin{array}{l}\text { Recuperação } \\
\text { Elástica (\%) }\end{array}$} & \multirow{2}{*}{$\begin{array}{l}\text { Grau de } \\
\text { Desempenho }\end{array}$} \\
\hline & & & $135^{\circ} \mathrm{C}$ & $150^{\circ} \mathrm{C}$ & $177^{\circ} \mathrm{C}$ & & \\
\hline CAP 30/45 & 31 & 53,2 & 468 & 226 & 78 & - & PG 64H-XX \\
\hline SBS 60/85E & 51 & 66,0 & 1611 & 695 & 253 & 87,5 & PG 76H-XX \\
\hline HiMA & 45 & 84,0 & 2170 & 997 & 309 & 96,0 & PG $82 \mathrm{H}-\mathrm{XX}$ \\
\hline
\end{tabular}

\subsection{ENVELHECIMENTO DE CURTO PRAZO}

Visando avaliar o efeito do envelhecimento nos ligantes asfálticos, foi utilizado o ensaio de envelhecimento em estufa de filme fino rotativo - RTFOT. Os ligantes foram envelhecidos em duas 
temperaturas de ensaio diferentes: (i) temperatura de $163^{\circ} \mathrm{C}$ de acordo com a norma ASTM D2872 (2012), com fluxo de ar controlado de 4,0 \pm 0,2 L/min durante 85 minutos; e (ii) temperatura de $180^{\circ} \mathrm{C}$, com as mesmas condições de fluxo de ar e duração do ensaio normatizado. A temperatura foi escolhida levando-se em consideração a temperatura de usinagem dos ligantes modificados em torno de $180^{\circ} \mathrm{C}$ (conforme indica o fabricante), a fim de se avaliar o efeito do aumento dessa temperatura nos ligantes modificados e no convencional.

\subsection{Ensaios reológicos}

Os ensaios reológicos foram realizados em um reômetro de cisalhamento dinâmico - DSR, modelo Discovery HR-3 da TA Instruments. Foram realizados os ensaios de varredura de frequência em diferentes temperaturas para a construção da curva mestra e do ensaio de varredura de deformação.

As curvas mestras apresentam a caracterização das propriedades viscoelásticas lineares dos ligantes asfálticos, monitorando as mudanças do comportamento do material em diferentes faixas de temperatura e frequência. Foram realizados ensaios de varredura de frequência de $1 \mathrm{rad} / \mathrm{s}$ a $100 \mathrm{rad} / \mathrm{s}$, sob deformação controlada de $0,01 \%$, nas temperaturas de $40{ }^{\circ} \mathrm{C}$ a $76{ }^{\circ} \mathrm{C}$, com incremento de $12{ }^{\circ} \mathrm{C}$, utilizando geometria de placas paralelas de diâmetro de $25 \mathrm{~mm}$ e gap de $1 \mathrm{~mm}$.

Os ensaios para determinar a região viscoelástica linear foram realizados por meio de uma varredura de deformações, baseado no procedimento do apêndice X1 (Teste para linearidade) da norma ASTM 7175 (2015). Porém, ao invés de ensaiar na temperatura alta do PG, variou-se a temperatura e aumentou-se a faixa de deformações. Os ensaios foram realizados nas temperaturas de $30{ }^{\circ} \mathrm{C}, 40^{\circ} \mathrm{C}, 50^{\circ} \mathrm{C}, 60^{\circ} \mathrm{C}$ e $70^{\circ} \mathrm{C}$, com varredura de deformação de $0 \%$ até $100 \%$ e frequência de $10 \mathrm{rad} / \mathrm{s}$.

\section{RESULTADOS E DISCUSSÕES}

\subsection{Curvas mestras}

As curvas mestras foram construídas a partir do princípio da superposição tempo-temperatura, utilizando como referência a temperatura de $40{ }^{\circ} \mathrm{C}$. A Figura 1 apresenta a comparação das curvas mestras do módulo de cisalhamento dinâmico e do ângulo de fase dos ligantes virgens.

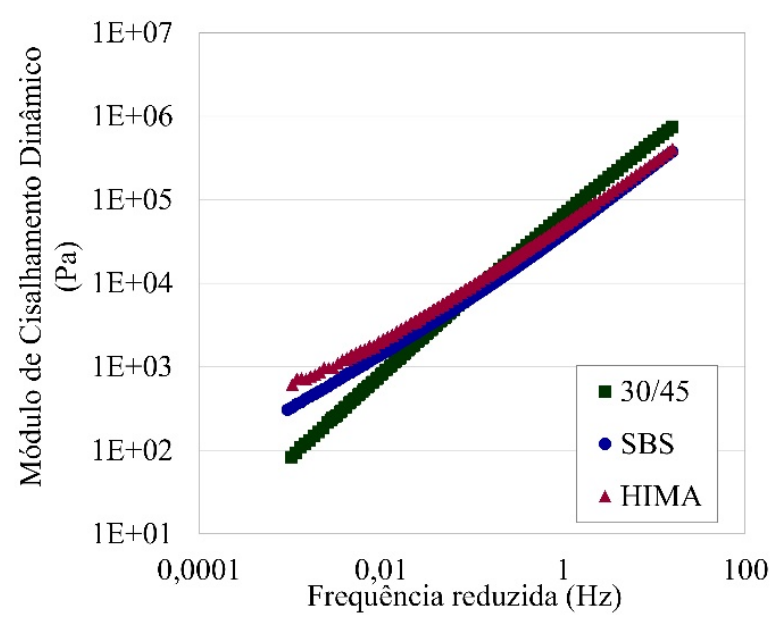

(a)

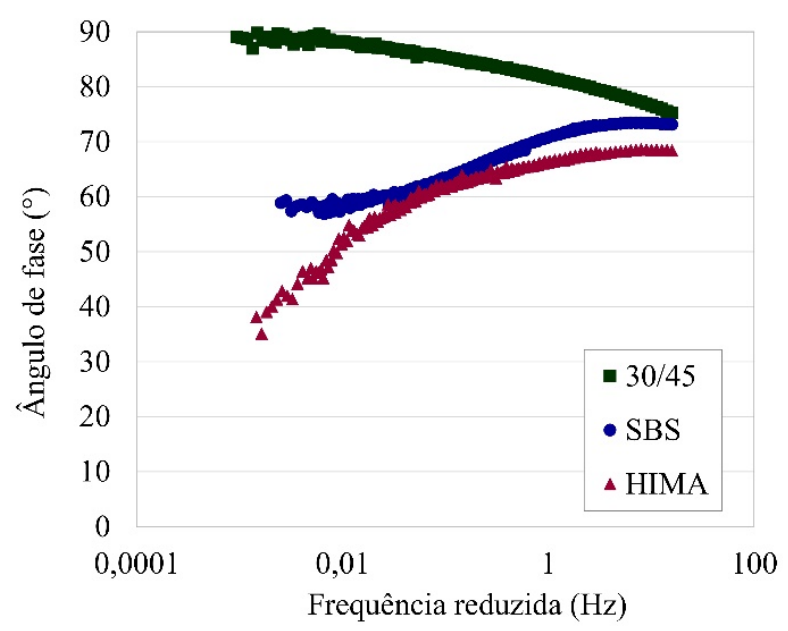

(b)

Figura 1. Curvas mestras: (a) módulo de cisalhamento dinâmico e (b) ângulo de fase dos três ligantes não envelhecidos 
Conforme esperado, o ligante 30/45 apresenta comportamento bem diferente dos ligantes modificados. Pela maior inclinação da curva mestra do módulo de cisalhamento dinâmico, é possível inferir que o ligante CAP 30/45 apresenta maior susceptibilidade térmica em relação aos outros materiais. Os dois ligantes modificados têm inclinações menores e sofrem menos com o efeito da variação de temperatura ou frequência de carregamento. A rigidez dos ligantes modificados é muito próxima na região de altas frequências (baixas temperatura) e se sobrepõe em alguns pontos. Porém, a grande diferença entre os ligantes é observada na região de baixas frequências (altas temperaturas), nas quais o ligante HiMA apresenta maior valor de $\left|G^{*}\right|$, o que pode indicar um melhor desempenho a deformação permanente em altas temperaturas, considerando que ligantes com elevada rigidez tendem a resistir melhor à deformação (Ahmedzade, 2013), enquanto que o ligante convencional apresenta a rigidez menor que os modificados em até uma ordem de grandeza.

0 ângulo de fase do ligante convencional tem o comportamento mais viscoso nas frequências baixas e tende a cair quanto maior a frequência. Já os ligantes modificados por polímero apresentam comportamento diferente: em frequências altas os ligantes estão mais elásticos, e tornam-se mais viscosos à medida que a frequência aumenta. Nos ligantes modificados, em frequências altas (temperaturas baixas), o ligante base é responsável pela maior parte da resposta do material. Conforme a temperatura aumenta, ou a frequência diminui, o ligante base torna-se pouco viscoso e deixa de resistir e, a partir daí, as redes de ligações do polímero são as responsáveis pelas respostas do material (Airey, 2003). Observa-se essa tendência ainda mais acentuada no ligante HiMA, pelo fato de o mesmo possuir mais polímero em sua composição.

As curvas mestras permitem avaliar a mudança de comportamento do material com os diferentes níveis de envelhecimento. Durante o ensaio RTFOT, o ligante asfáltico passa por um processo de oxidação, o que confere maior rigidez ao ligante. A comparação das propriedades reológicas para cada ligante asfáltico, nos três níveis de envelhecimento (virgem, após RTFOT $163^{\circ} \mathrm{C}$ e após RTFOT $180^{\circ} \mathrm{C}$ ) é apresentada na Figura 2. A partir dos resultados, é possível verificar o aumento da rigidez a partir do valor do módulo de cisalhamento dinâmico, que aumenta conforme o aumento do nível de envelhecimento. Na Figura 2(a), devido à semelhança das curvas mestras apresentadas para as duas condições de envelhecimento, adicionou-se no canto superior esquerdo o mesmo resultado em escala linear, para que fosse possível visualizar uma pequena diferença entre as duas condições.

No entanto, no caso do ligante 30/45 (Figura 2(a)), o aumento da temperatura de ensaio para $180{ }^{\circ} \mathrm{C}$ não apresentou diferença significativa com relação ao ensaio a $163^{\circ} \mathrm{C}$. Como a temperatura de usinagem normalmente utilizada para este ligante é em torno de $160{ }^{\circ} \mathrm{C}$ (Motta, 2011; Vasconcelos et al., 2011, dos Santos Bastos et al., 2015), pode-se inferir que a temperatura do ensaio RTFOT a $163^{\circ} \mathrm{C}$ já promoveu o envelhecimento sofrido pelo ligante durante a usinagem e que a elevação da temperatura para $180^{\circ} \mathrm{C}$, com as mesmas condições de ensaio (fluxo de ar e duração), não implicou em uma alteração significativa na rigidez do material.

Yan et al. (2017) constatam em seu estudo que não houve diferenças significativas entre o envelhecimento de um ligante asfáltico puro no ensaio RTFOT a $178{ }^{\circ} \mathrm{C}$ comparado ao mesmo ensaio realizado a temperatura de $193{ }^{\circ} \mathrm{C}$, ainda que o teor de carbonila difira entre os ligantes, mostrando que o aumento da temperatura nesse ensaio não implicou em um maior grau de oxidação, e que o envelhecimento, neste caso, pode não estar diretamente relacionado com o parâmetro de rigidez. Dessa forma, a análise química dos ligantes envelhecidos faz-se necessária para uma melhor compreensão dos resultados obtidos. 

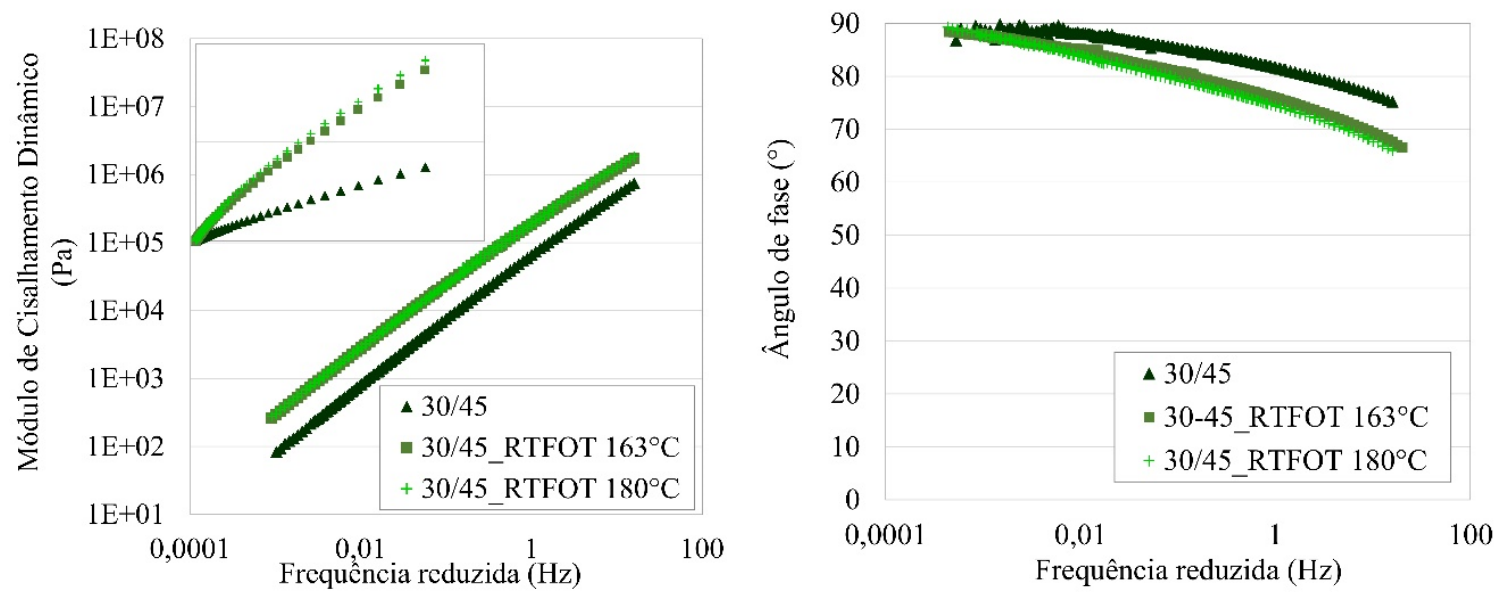

(a)
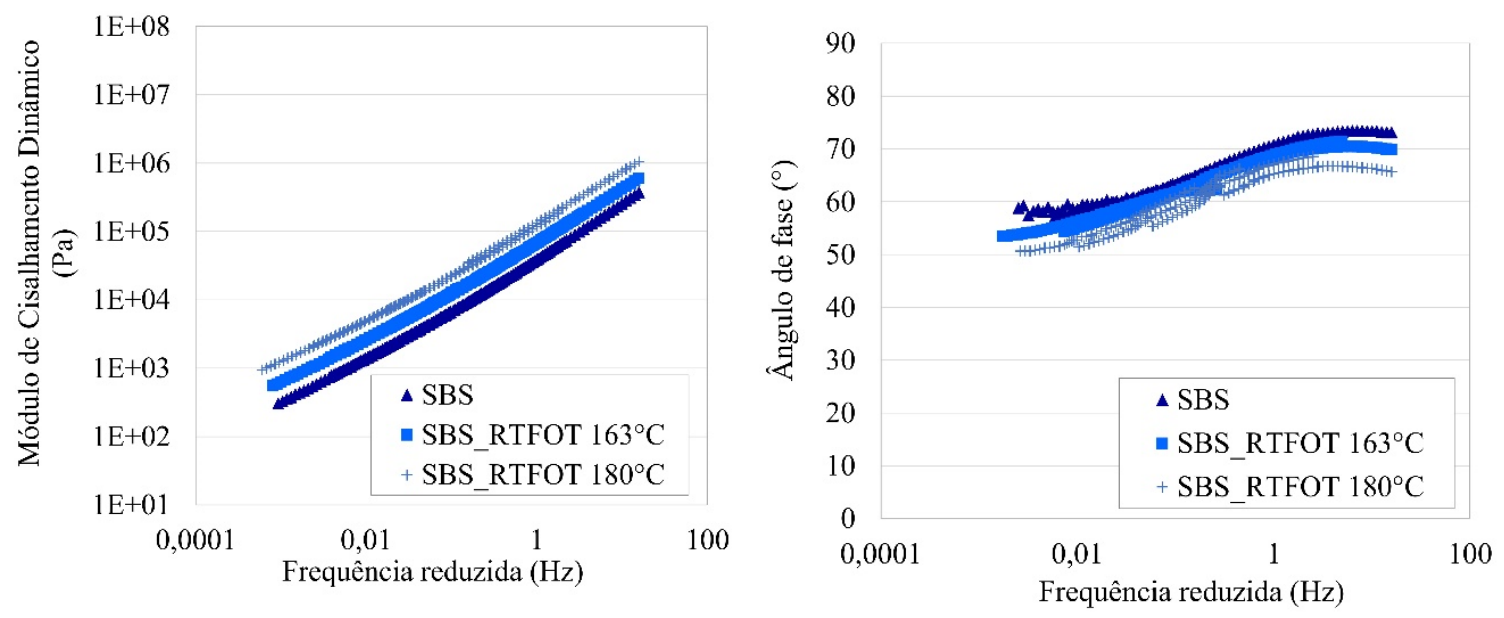

(b)
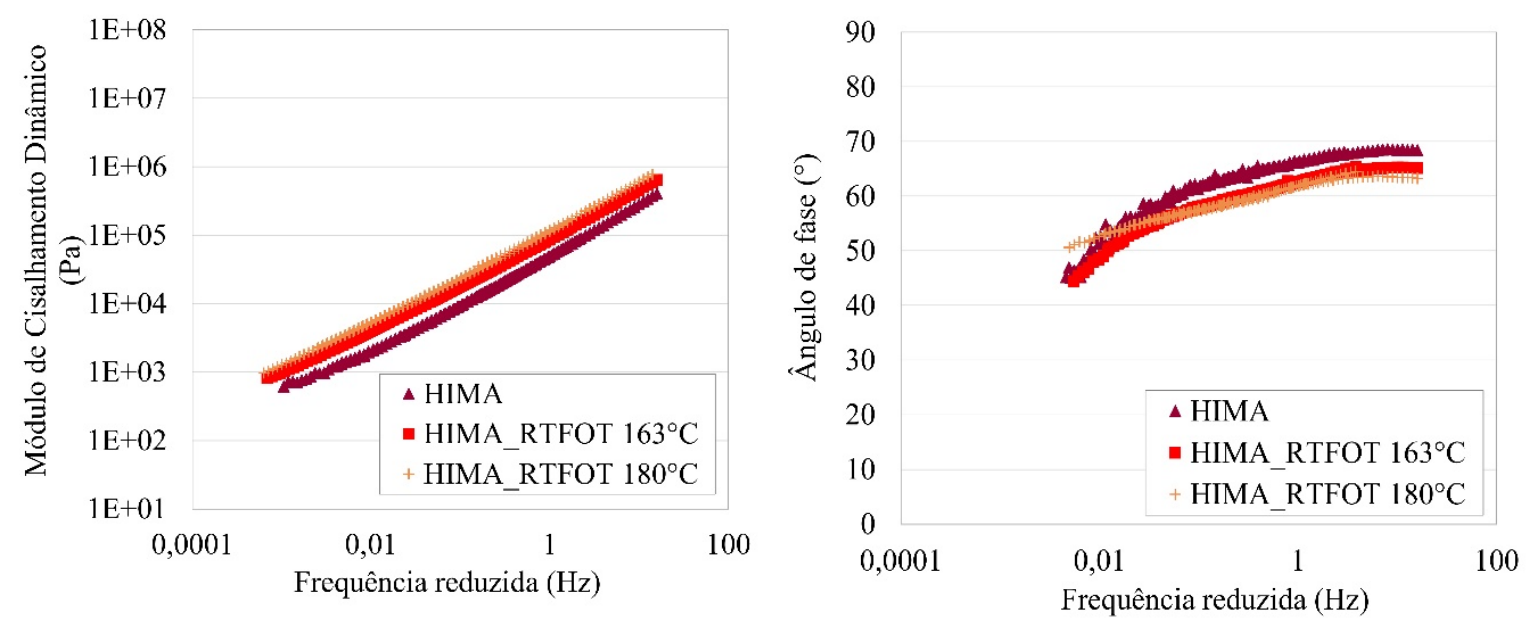

(c)

Figura 2. Curvas mestras do módulo de cisalhamento dinâmico e do ângulo de fase, para cada ligante, nos diferentes níveis de envelhecimento: (a) ligante 30/45, (b) ligante SBS e (c) ligante HiMA

Por outro lado, é possível observar que o ensaio RTFOT a $163{ }^{\circ} \mathrm{C}$ tem maior influência no ligante convencional 30/45, provocando um maior grau de envelhecimento nesse ligante quando comparado ao grau de envelhecimento dos ligantes modificados após o ensaio. Yan et al. (2017) demostram que quanto maior o teor de polímero no ligante asfáltico, maior a sua 
viscosidade, o que dificulta o espalhamento do ligante dentro do frasco do ensaio RTFOT e, portanto, pode diminuir o grau de envelhecimento do mesmo durante o ensaio RTFOT a $163{ }^{\circ} \mathrm{C}$. Outros autores também constataram a mesma dificuldade da formação do filme de ligante nos frascos devido à alta viscosidade, e sugerem a utilização de esferas ou barras cilíndricas de aço, ou o aumento da temperatura do ensaio para facilitar o espalhamento do ligante (Bahia et al., 2001; Jia et al., 2005). Seguindo essa tendência, os ligantes modificados por polímeros apresentaram um maior envelhecimento após o ensaio RTFOT a $180^{\circ} \mathrm{C} .0$ aumento da temperatura permitiu a formação do filme de ligante, expondo melhor o ligante ao fluxo de ar e temperatura.

A curva mestra do ângulo de fase para o ligante convencional em diferentes níveis de envelhecimento é apresentada na Figura 2(a). 0 comportamento do ligante virgem é muito próximo ao comportamento viscoso em todas as condições de ensaio, inclusive em frequências altas. Assim como aconteceu com o $\left|G^{*}\right|$, os ligantes envelhecidos a $163^{\circ} \mathrm{C}$ e $180{ }^{\circ} \mathrm{C}$ apresentaram os resultados de ângulo de fase muito próximos, indicando o mesmo comportamento independente da temperatura de ensaio no RTFOT. Nota-se que nas frequências altas, os ligantes envelhecidos tiveram o ângulo de fase um pouco menor que o ligante virgem, indicando o comportamento mais elástico após o envelhecimento. Nas frequências baixas, equivalente a altas temperaturas, a aumento do nível de envelhecimento não alterou o comportamento do ligante, e para as mesmas frequências, as três condições apresentaram o ângulo de fase muito próximo a $90^{\circ}$.

Na Figura 2(b) apresentam-se os resultados para o ligante modificado por SBS nos três níveis de envelhecimento. Os maiores valores para o ângulo de fase são os do SBS não envelhecido. Conforme aumenta-se a temperatura de envelhecimento, o ângulo de fase diminui, indicando continuidade no processo de oxidação com a temperatura e uma maior elasticidade. A diferença de comportamento entre os ligantes virgens e os envelhecidos se torna mais evidente nas extremidades das curvas, tanto em frequências altas, quanto nas frequências mais baixas. Um aumento do valor de $\left|G^{*}\right|$ e redução do ângulo de fase são mudanças favoráveis a deformação permanente; no entanto, essas mudanças são desfavoráveis para o desempenho a fadiga e trincamento térmico.

A Figura 2(c) apresenta as curvas mestras para o ligante altamente modificado (HiMA). Ao observar o ângulo de fase nas frequências altas, o comportamento já era esperado, uma vez que o ligante virgem apresenta comportamento mais próximo ao viscoso, enquanto os ligantes envelhecidos apresentam-se mais elásticos. Nas frequências intermediárias, apesar dos dois ligantes envelhecidos (a $163{ }^{\circ} \mathrm{C}$ e $180^{\circ} \mathrm{C}$ ) se sobreporem, seus valores de ângulo de fase foram menores do que o ligante virgem. Porém, em frequências baixas, o ângulo de fase para o ligante HiMA envelhecido a $180{ }^{\circ} \mathrm{C}$ sofreu inversão. $\mathrm{O}$ ligante oxidado a $180{ }^{\circ} \mathrm{C}$ apresentou comportamento mais viscoso em relação ao ligante oxidado a $163^{\circ} \mathrm{C}$ e ao ligante virgem, nessa sequência. Na curva do ângulo de fase para o envelhecimento a $180^{\circ} \mathrm{C}$, pode-se observar que ela está iniciando uma região de plateau. Wu et al. (2009) observam um comportamento similar para uma varredura de temperaturas em ligantes envelhecidos modificados por SBS. Os autores associam a região de plateau no ângulo de fase como um indicador de dano na matriz polimérica devido ao envelhecimento. A diferença nas tendências dos ligantes SBS e HiMA para a temperatura de $180{ }^{\circ} \mathrm{C}$ pode estar associada a quantidade superior de polímero presente no HiMA, uma vez que o polímero sofre degradação durante o processo de envelhecimento (Lu e Isacsson, 1998; Lu e Isacsson, 2000; Cortizo et al., 2004; Wu et al., 2009). Além disso, a exposição a altas 
temperaturas em presença do oxigênio presente na atmosfera pode causar reações de ligações cruzadas do polímero SBS (Lu e Isacsson, 1998; Cortizo et al., 2004).

\subsection{Região viscoelástica linear}

De acordo com a norma ASTM 7175 (2015), o material não está mais no regime viscoelástico linear quando o valor do módulo de cisalhamento dinâmico atinge $90 \%$ do seu valor inicial em um ensaio de varredura de tensões/deformações. Por outro lado, o Relatório 369 do SHRP (1994) sugere considerar uma queda de apenas 5\% do valor inicial. Para caracterizar melhor o comportamento viscoelástico linear dos materiais, optou-se por aumentar a faixa de deformações, variando-se a temperatura, ao invés de realizar os ensaios apenas na temperatura alta do PG, avaliando-se dessa forma a influência tanto do envelhecimento quanto da temperatura na LVER dos ligantes asfálticos. A Figura 3 ilustra o método utilizado, considerando o limite de $90 \%$ do valor inicial de $\left|G^{*}\right|$ pela norma da ASTM.

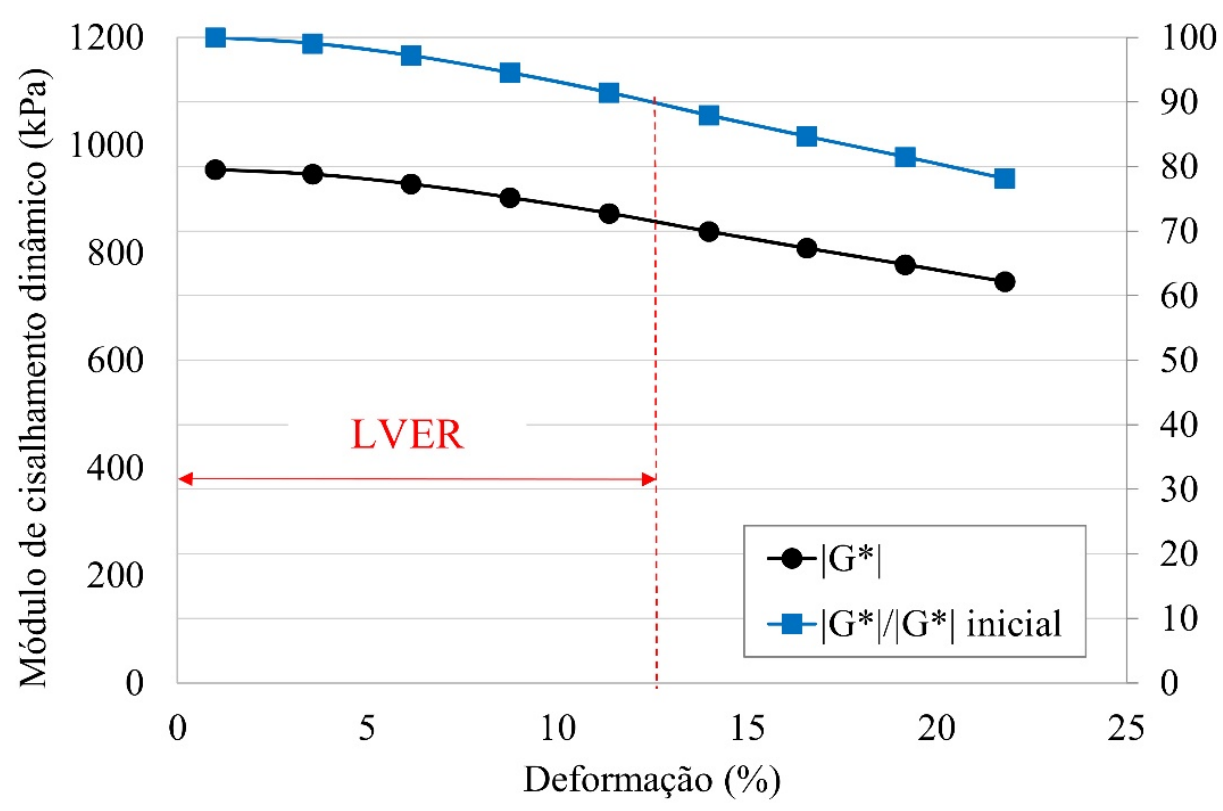

Figura 3. Varredura de deformação para determinação da LVER

A Figura 4 apresenta os valores limites de deformação, resultantes do ensaio de varredura de deformação para: (i) 90\% do módulo de cisalhamento dinâmico ( $\left|G^{*}\right|$ ) inicial, de acordo com a ASTM 7175(2015) e (ii) 95\% módulo de cisalhamento dinâmico inicial, conforme Relatório 369 do SHRP. São apresentados os resultados para os três ligantes estudados, nos três níveis de envelhecimento, para as temperaturas de $30^{\circ} \mathrm{C}, 40^{\circ} \mathrm{C}$ e $50^{\circ} \mathrm{C}$. Em algumas condições de envelhecimento, nas temperaturas de $60^{\circ} \mathrm{C}$ e $70{ }^{\circ} \mathrm{C}$, não foram verificados os limites da zona viscoelástica linear dentro da faixa de deformação avaliada (0\% a 100\%), dessa forma os resultados não são apresentados para essas temperaturas. Nas condições que foram possíveis verificar os limites de deformação, foi observada a mesma tendência de crescimento com o aumento da temperatura. Os resultados do ligante SBS virgem (pelos dois critérios) e SBS RTFO $63^{\circ} \mathrm{C}$ (critério de $90 \%\left|G^{*}\right|$ ) também apresentaram os limites de deformação acima de 100\%, fora da faixa de deformação avaliada, na temperatura de $50{ }^{\circ} \mathrm{C}$. 


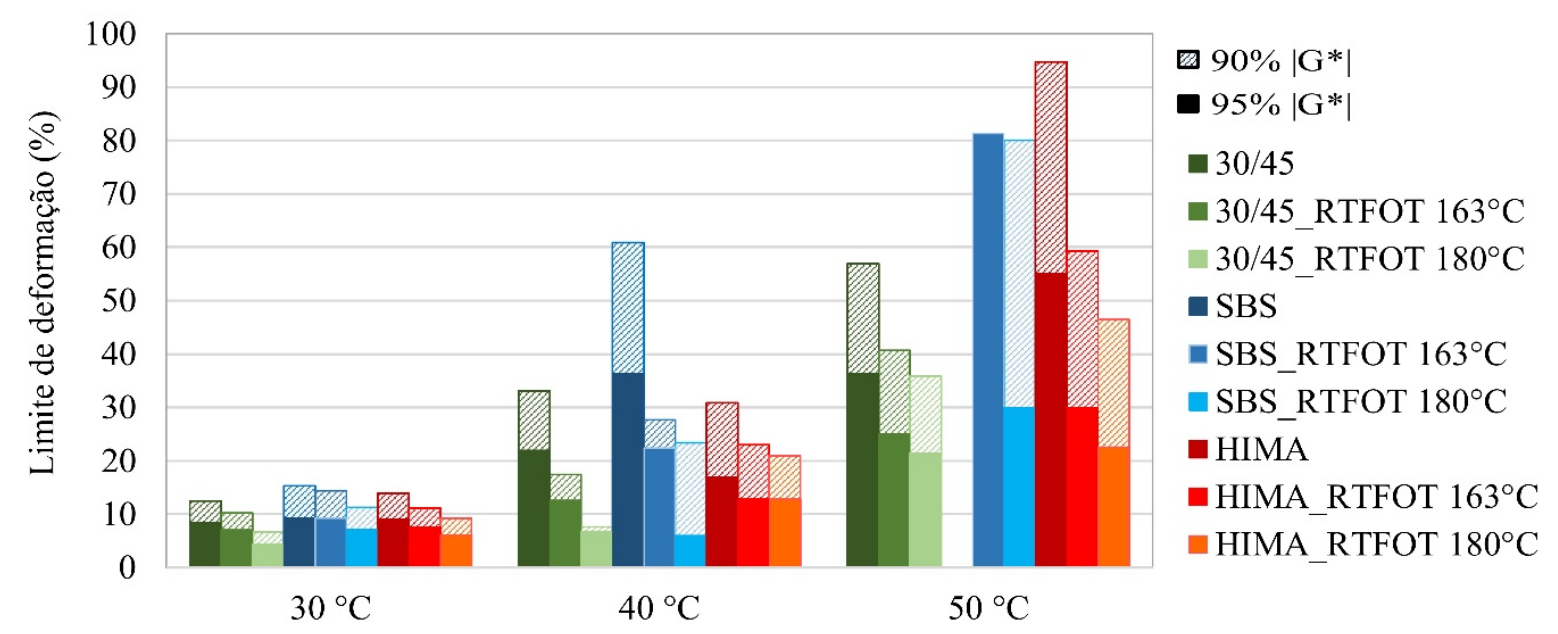

Figura 4. Limites de deformação dos ligantes asfálticos, nos diferentes níveis de envelhecimento, em diferentes temperaturas, a partir dos dois critérios de avaliação (90\% |G*| e 95\% |G*|)

A partir dos resultados apresentados na Figura 4, verifica-se que a temperatura de ensaio tem grande influência no limite de deformação da região viscoelástica dos ligantes asfálticos. Quanto maior a temperatura, maior o limite de deformação antes de o ligante sair do regime viscoelástico linear. Por outro lado, quanto maior o nível de envelhecimento do ligante asfáltico, menor é o limite de deformação. Os ligantes modificados apresentaram maiores LVER que o ligante convencional principalmente em altas temperaturas, aproximando-se com a diminuição da temperatura de ensaio e o aumento do nível de envelhecimento.

Os resultados mostram que ambos, tanto a temperatura como o nível de envelhecimento, possuem influência sobre as propriedades viscoelásticas dos ligantes asfálticos, apresentando comportamento mais viscoso com o aumento da temperatura e mais elástico com a diminuição da mesma, sendo essa relação inversa para o nível de envelhecimento que tende a enrijecer o ligante asfáltico. Desse modo, a propriedade de rigidez dos ligantes asfálticos utilizada pela norma da ASTM 7175 (2015) e pelo Relatório 369 do SHRP para determinação da LVER sofre grande influência desses dois parâmetros. Como já previsto, os valores limites de deformação para o critério SHRP mostram-se bem mais restritivos para determinação da região viscoelástica dos materiais asfálticos, apresentando maior variação entre os critérios nas temperaturas mais elevadas.

Da Figura 4 é possível observar ainda que a limitação da LVER é mais significativa para baixas temperaturas de ensaio, agravada ainda mais pelo aumento do grau de envelhecimento. Apesar da norma ASTM 7175 (2015) afirmar a necessidade da verificação da LVER, o Apêndice X1 (Testing for linearity) se restringe apenas a ligantes não envelhecidos, avaliando seu comportamento (linear ou não linear) em altas temperaturas $52{ }^{\circ} \mathrm{C}$ a $82^{\circ} \mathrm{C}$. Os resultados demostram que a avaliação considerando o nível de envelhecimento e temperatura é importante para a correta limitação da LVER, de forma a obter corretamente as propriedades viscoelásticas dos materiais avaliados. A determinação precisa da região viscoelástica linear, assim como a região não-linear, é relevante para se conhecer a região onde ocorre mudança de comportamento no material, de forma a estabelecer os parâmetros adequados para os ensaios de dano e poder avaliar o comportamento do material em campo. 


\section{CONCLUSÕES}

O presente estudo avaliou as propriedades viscoelásticas de três ligantes asfálticos (sendo um convencional e dois modificados) em diferentes condições de envelhecimento. Determinou-se o valor limite de deformação da região viscoelástica linear para cada ligante, nos diferentes níveis de envelhecimento e temperatura. A seguir são apresentadas as principais conclusões observadas:

- A partir dos resultados de curva mestra, foi verificado que para o CAP 30/45, o aumento da temperatura do ensaio RTFOT de $163^{\circ} \mathrm{C}$ para $180^{\circ} \mathrm{C}$, para as mesmas condições de ensaio (fluxo de ar e duração), não influenciou a rigidez do material de forma significativa (porém alguma mudança no ângulo de fase), no entanto, pode ter havido alteração na estrutura química, sendo necessárias outras análises para essa verificação.

- O CAP 30/45 apresenta maior susceptibilidade térmica em relação aos outros materiais, enquanto o HiMA apresenta a maior rigidez em baixas frequências (altas temperaturas). Os ligantes modificados apresentaram maiores LVER que o ligante convencional, principalmente em altas temperaturas. 0 aumento do nível de envelhecimento e a redução da temperatura de ensaio diminui a diferença entre os valores limites de LVER de ligantes convencionas e modificados.

- 0 aumento da temperatura melhorou a formação do filme de ligante dentro dos frascos do ensaio RTFOT para os ligantes asfálticos modificados, expondo melhor o ligante ao fluxo de ar e temperatura. Por essa razão, os ligantes modificados por polímeros apresentaram um aumento na rigidez devido ao envelhecimento após o ensaio RTFOT a $180^{\circ} \mathrm{C}$.

- A temperatura influencia diretamente na determinação do limite da região viscoelástica linear dos ligantes asfálticos, enquanto que o nível de envelhecimento do ligante asfáltico possui relação inversamente proporcional. A limitação da LVER é mais significativa para baixas temperaturas de ensaio, acentuada pelo aumento do grau de envelhecimento.

- A correta determinação da LVER é de extrema importância para caracterização das propriedades reológicas dos ligantes asfálticos, assim como a separação das regiões nãolinear e de dano, de forma a estabelecer adequadamente os parâmetros para os ensaios de dano.

\section{REFERÊNCIAS}

AASHTO (2014) AASHTO Designation M332-14: Standard specification for performance-graded. American Association of State Highway and Transportation Officials, Washington, DC.

AHMEDZADE, P. (2013) The investigation and comparison effects of SBS and SBS with new reactive terpolymer on the rheological properties of bitumen. Construction and Building Materials, v. 38, p. 285-291. DOI: 10.1016/j.conbuildmat.2012.07.090

AIREY, G. D. (2003) Rheological properties of styrene butadiene styrene polymer modified road bitumens. Fuel, v. 82, n. 14, p. 1709-1719. DOI: 10.1016/S0016-2361(03)00146-7

AIREY, G. D.; RAHIMZADEH, B.; COLLOP, A. (2003) Linear viscoelastic performance of asphaltic materials. Road Materials and Pavement Design, v. 4, n. 3, p. 269-292. DOI: 10.1080/14680629.2003.9689949

ANDERSON, D. A., CHRISTENSEN, D. W., BAHIA, H. U., DONGRE, R., SHARMA, M. G., ANTLE, C. E., BUTTON, J. (1994) Binder characterization and evaluation, volume 3: Physical characterization. Strategic Highway Research Program, National Research Council, Report No. SHRP-A-369.

ANP (2010) - Agência Nacional do Petróleo, Gás Natural e Biocombustíveis. Cimentos Asfálticos de Petróleo. Resolução n 32 de 21 de setembro de 2010 - Regulamento Técnico $n^{\circ} 04 / 2010$

ASTM D2872-12 $\mathrm{e}^{\mathrm{1}}$ - Standard Test Method for Effect of Heat and Air on a Moving Film of Asphalt (Rolling Thin-Film Oven Test), versão corrigida Fev. 2013. 
ASTM D7175-15 - Standard Test Method for Determining the Rheological Properties of Asphalt Binder Using a Dynamic Shear Rheometer, 2015.

BAHIA, H. U.; HANSON, D. I.; ZENG, M.; ZHIA, H.; KHATRI, M.A.; ANDERSON, R. M. (2001) NCHRP Report 459: Characterization of Modified Asphalt Binders in Superpave Mix Design. TRB, National Research Council, Washington, D.C.

BAHIA, H. U., ZHAI, H., BONNETTI, K., KOSE, S. (1999) Non-linear viscoelastic and fatigue properties of asphalt binders. Journal of the Association of Asphalt Paving Technologists, v. 68, p. 1-34.

BRESSI, S., CARTER, A., BUECHE, N., DUMONT, A. G. Impact of different ageing levels on binder rheology. International Journal of Pavement Engineering, v. 17, n. 5, p. 403-413, 2016. DOI: 10.1080/10298436.2014.993197

CASTELO BRANCO, V. T. F. (2008) A unified method for the analysis of nonlinear viscoelasticity and fatigue cracking of asphalt mixtures using the dynamic mechanical analyzer, Tese (Doutorado). College Station, Texas: Texas A\&M University.

CORTIZO, M. S., LARSEN, D. O., BIANCHETTO, H., \& ALESSANDRINI, J. L. (2004) Effect of the thermal degradation of SBS copolymers during the ageing of modified asphalts. Polymer Degradation and Stability, v. 86, n. 2, p. 275-282. DOI: 10.1016/j.polymdegradstab.2004.05.006

DI BENEDETTO, H.; NGUYEN, Q. T.; SAUZÉAT, C. (2011) Nonlinearity, heating, fatigue and thixotropy during cyclic loading of asphalt mixtures. Road Materials and Pavement Design, v. 12, n. 1, p. 129-158. D0I: 10.1080/14680629.2011.9690356

DIAB, A.; YOU, Z. (2017) Small and large strain rheological characterizations of polymer-and crumb rubber-modified asphalt binders. Construction and Building Materials, v. 144, p. 168-177. DOI: 10.1016/j.conbuildmat.2017.03.175

DOS SANTOS BASTOS, J. B.; BORGES, R. L.; SOARES, J. B.; KLINSKY, L. M. G. (2015) Avaliação em laboratório e em campo da deformação permanente de pavimentos asfálticos do Ceará e de São Paulo. TRANSPORTES, v. 23, n. 3, p. 44-55. DOI: $10.14295 /$ transportes.v23i3.914

GRILLI, A.; GNISCI, M. I.; BOCCI, M. (2017) Effect of ageing process on bitumen and rejuvenated bitumen. Construction and Building Materials, v. 136, p. 474-481. DOI: 10.1016/j.conbuildmat.2017.01.027

JIA, J.; ZHANG, X.; YUAN, Y. (2005) Rolling thin film oven test investigation for polymer modified asphalt. Journal of Harbin Institute of Technology, v. 12, n. 6, p. 635-638.

KENNEDY, T. W., HUBER, G. A., HARRIGAN, E. T., COMINSKY, R. J., HUGHES, C. S., VON QUINTUS, H., MOULTHROP, J. S. (1994) Superior performing asphalt pavements (Superpave): The product of the SHRP asphalt research program. Washington, DC, USA: Strategic Highway Research Program, National Research Council.

KIM, Y.; LITTLE, D. N.; LYTTON, R. L. (2003) Fatigue and healing characterization of asphalt mixtures. Journal of Materials in Civil Engineering, v. 15, n. 1, p. 75-83. DOI: 10.1061/(ASCE)0899-1561(2003)15\%3A1(75).

LU, X., ISACSSON, U. (1998) Chemical and rheological evaluation of ageing properties of SBS polymer modified bitumens. Fuel, v. 77, n. 9-10, p. 961-972. DOI: 10.1016/S0016-2361(97)00283-4

LU, X., ISACSSON, U. (2000) Artificial aging of polymer modified bitumens. Journal of Applied Polymer Science, v. 76, n. 12, p. 1811-1824. DOI: 10.1002/(SICI)1097-4628(20000620)76:12<1811::AID-APP12>3.0.CO;2-1

LUCENA, M. D. C. C., SOARES, J. B., SOARES, B. J., \& LEITE, L. F. M. (2004) Reologia de asfaltos brasileiros puros e modificados por SBS. In: XVIII Congresso de Pesquisa e Ensino em Transportes.

MANGIAFICO, S., SAUZÉAT, C., DI BENEDETTO, H., POUGET, S., OLARD, F., PLANQUE, L. (2015) Quantification of biasing effects during fatigue tests on asphalt mixes: non-linearity, self-heating and thixotropy. Road Materials and Pavement Design, v. 16, n. sup2, p. 73-99. DOI: 10.1080/14680629.2015.1077000

MARASTEANU, M. O.; ANDERSON, D. A. (2000) Establishing linear viscoelastic conditions for asphalt binders. Transportation Research Record: Journal of the Transportation Research Board, v. 1728, n. 1, p. 1-6. D0I: 10.3141/1728-01

MASAD, E., HUANG, C. W., AIREY, G., MULIANA, A. (2008) Nonlinear viscoelastic analysis of unaged and aged asphalt binders. Construction and Building Materials, v. 22, n. 11, p. 2170-2179. DOI: 10.1016/j.conbuildmat.2007.08.012

MOTTA, R. S. (2011) Estudo de misturas asfálticas mornas em revestimentos de pavimentos para redução de emissão de poluentes e de consumo energético. 2011. 243p. Tese (Doutorado) - Escola Politécnica da Universidade de São Paulo. São Paulo. DOI: 10.11606/T.3.2011.tde-19072011-170629

PADMAREKHA, A.; KRISHNAN, J. M. (2013) Viscoelastic transition of unaged and aged asphalt. Journal of Materials in Civil Engineering, v. 25, n. 12, p. 1852-1863. DOI: 10.1061/(ASCE)MT.1943-5533.0000734

PETERSEN, J. C.; ROBERTSON, R. E.; BRANTHAVER, J. F.; HARNSBERGER, P. M.; DUVALL, J. J.; KIM, S. S.; ANDERSON, D. A.; CHRISTIANSEN, D. W.; BAHIA, H. U. (1994) Binder characterization and evaluation: Volume 1. Rep. No. SHRP-A-367, Strategic Highway Research Program, National Research Council, Washington, DC.

READ, J.; WHITEOAK, D. (2003) The shell bitumen handbook. Thomas Telford, 2003.

SARAVANAN, U. (2012) On the use of linear viscoelastic constitutive relations to model asphalt. International Journal of Pavement Engineering, v. 13, n. 4, p. 360-373. DOI: 10.1080/10298436.2011.599386

VASCONCELOS, K. L.; BERNUCCI, L. L. B.; MOURA, E.; SANBONSUGE, K.; CHAVES, J. M. (2011) Caracterização Mecânica de Misturas Asfálticas Contínuas e Descontínuas com Diferentes Ligantes Asfálticos. In $7^{\circ}$ Congresso Brasileiro de Rodovias e Concessões-CBR\&C.

WU, S. P., PANG, L., MO, L. T., CHEN, Y. C., ZHU, G. J. (2009) Influence of aging on the evolution of structure, morphology and rheology of base and SBS modified bitumen. Construction and Building Materials, v. 23, n. 2, p. 1005-1010. DOI: $10.1016 /$ j.conbuildmat.2008.05.004

YAN, C.; HUANG, W.; TANG, N. (2017) Evaluation of the temperature effect on Rolling Thin Film Oven aging for polymer modified asphalt. Construction and Building Materials, v. 137, p. 485-493. DOI: 10.1016/j.conbuildmat.2017.01.135 